\title{
LEITURA DE TEXTO IMAGÉTICO EM LÍNGUA INGLESA E A CONSTRUÇÃO DE SIGNIFICADOS A PARTIR DE RECURSOS \\ SEMIÓTICOS
}

\author{
ENGLISH VISUAL TEXT READING AND MEANING MAKING FROM \\ SEMIOTIC RESOURCES
}

Sheilla Andrade de Souza (IFMG-Ipatinga)

souza_sh@hotmail.com

\begin{abstract}
RESUMO: É certo que as tecnologias digitais favoreceram a construção de textos orais e escritos, a partir de diferentes recursos de comunicação, sendo eles: palavras, sons, imagens, cores, diagramação, movimento. Assim, aumenta-se a noção de texto como sendo produto de escolhas, decisões, edições, conteúdo. Nessa perspectiva, o texto é o resultado de um trabalho semiótico. Com base nisso, este artigo consiste em um recorte de uma tese desenvolvida no Programa de Pós-Graduação em Estudos de Linguagens do Centro Federal de Educação Tecnológica de Minas Gerais - CEFET-MG. Objetiva-se discutir e apresentar uma proposta de atividade que consistiu na prática de leitura de texto imagético composto por múltiplos modos semióticos. A metodologia utilizada na pesquisa foi a Pesquisa Participante. Como resultado, percebeu-se que os alunos foram além da decodificação do código verbal e simples localização de informação. Eles apoiaram-se em experiências individuais, conhecimento de mundo e contexto social para a construção de sentido.
\end{abstract}

PALAVRAS-CHAVE: prática de leitura; texto imagético; construção de significado.

\begin{abstract}
It is true that digital technologies facilitated the construction of oral and written texts, based on different communication resources, namely: words, sounds, images, colors, diagramming, movement. Thus, the notion of text is increased as a product of choices, decisions, editions, content. In this perspective, the text is the result of semiotic work. Based on that, this article consists of an excerpt from a thesis developed at Programa de PósGraduação em Estudos de Linguagens do Centro Federal de Educação Tecnológica de Minas Gerais - CEFET-MG. It aims to discuss and present an activity proposal that consisted of reading visual text composed of multiple semiotic modes. The methodology used in the research was participant research. As a result, it was possible to observe that the students went beyond decoding the verbal code and simply locating information. They relied on individual experiences, knowledge of the world and social context for meaning making.
\end{abstract}

KEYWORDS: reading practice; visual text; meaning making. 


\section{Introdução}

Os textos contemporâneos estão se tornando cada vez mais visuais. Imagens, palavras, cores, som, movimentos se combinam para a construção de sentido, e as ferramentas digitais desempenham um papel fundamental nesse processo, no sentido de facilitar a construção dos textos imagéticos a partir da integração dos diversos modos semióticos.

Assim sendo, entendo que o papel da escola seja desenvolver práticas de leitura e de escrita que abordem essa questão e permitam aos alunos perceberem que cada elemento integrante de um texto visual possui significado e razão por fazer parte do texto. Reconheço que essa não seja uma tarefa fácil, pois, ainda, na escola, as práticas de textos predominantemente verbais imperam. O que se distancia disso pode ser mal interpretado e gerar insatisfação por parte dos alunos, como exemplo do que ocorreu durante o desenvolvimento desta pesquisa, já que houve resistência dos participantes em realizar atividades de leitura e escrita de textos imagéticos (ver Souza (2019)).

Neste artigo, apresento uma atividade de leitura que buscou conscientizar os alunos sobre os diversos elementos que compõem um texto e que necessitam ser lidos para a construção de sentidos. A proposta se apoia nas discussões referentes à construção de sentido com base nos estudos de Halliday e Hasan (1989), Hodge e Kress (1988), Kress (2003, 2010) e Kress e van Leeuwen (2006). Em um primeiro momento, apresento uma breve reflexão referente à Linguística Sistêmico-Funcional. Na sequência, discuto termos importantes relacionados à Semiótica Social. Em seguida, discorro sobre a metodologia utilizada na pesquisa. Posteriormente, explico a proposta de atividade de texto imágetico seguido da análise dos dados. Por fim, teço as considerações finais.

\section{Linguística sistêmico-funcional: uma reflexão}

A Linguística Sistêmico-Funcional (LSF) originou-se a partir dos estudos de Michael Alexander Kirkwood Halliday nas décadas de 1960 e 1970, dentro de uma visão sociossemiótica de língua e de linguagem. Halliday se preocupou em estudar como as pessoas utilizam a língua e a linguagem para expressar os significados e como interagem por meio delas. É importante esclarecer que, para Halliday, língua e linguagem são conceitos distintos. Nesse sentido, para Halliday e Matthiessen (2004, p. 31, tradução minha), “[...] a análise sistêmica revela que a funcionalidade está intrínseca na linguagem: ou seja, toda arquitetura da linguagem está organizada em linhas funcionais. A linguagem se configura a partir das 
funções que desempenha e tem evoluído na espécie humana."1

Neves (1994) afirma que qualquer abordagem funcionalista interessa-se pela investigação de como a comunicação acontece por meio da língua e da linguagem. Em outros termos, como os usuários de uma determinada língua se comunicam: exercem práticas de linguagem. Para Resende e Ramalho (2006),

[...] entender o uso da linguagem como prática social implica compreendê-lo como um modo de ação historicamente situado, que tanto é construído socialmente como também é constituído de identidades sociais, relações sociais e sistemas de conhecimento e crença (RESENDE; RAMALHO, 2006, p. 26).

Já a língua é vista como “[...] um recurso para a produção de significado, que reside nos padrões sistêmicos de escolha" "2 (HALLIDAY; MATTHIESSEN, 2004, p. 23, tradução minha) e se apoia na noção de função. Dizer que a LSF é sistêmica significa considerar a "[...] língua como uma rede de sistemas interligados que o falante faz uso (base funcional) para produzir significados (base semântica) em situações de comunicação" (SANTOS, 2014, p. 166). Na visão de Santos (2014, p. 166), “[...] o que interessa ao linguista sistêmico é analisar quais escolhas linguísticas foram feitas em um determinado contexto de comunicação e como essas escolhas produzem significados". Ainda para a autora, as escolhas nos sistemas da língua não são aleatórias, mas carregadas de valores sociais. Nessa perspectiva, a língua é concebida

[...] como um instrumento de comunicação que não pode ser analisado como um objeto autônomo, mas como uma estrutura maleável, sujeita a pressões oriundas das diferentes situações comunicativas, que ajudam a determinar sua estrutura gramatical (MARTELOTTA; KENEDY, 2015, p. 14).

É necessário trazer para a discussão definições de texto dentro da linha de pensamento aqui exposta. Halliday (1979) entende como texto os casos de interação linguística na qual as pessoas participam efetivamente, ou seja, tudo o que se fala e o que se escreve em um contexto operatório, em oposição a um contexto de palavras ordenadas, como, por exemplo, o que ocorre nos dicionários. Para o autor, o texto representa uma opção: é o que se deseja dizer e que se materializa por meio de um conjunto de escolhas. Dentro de uma perspectiva funcional, texto é unidade semântica diferente de um conjunto de sentenças isoladas; é a língua e a linguagem em seu uso funcional, que desempenha alguma função no contexto; o

\footnotetext{
${ }^{1}$ No original: “[...] the systemic analysis shows that functionality is intrinsic to language: that is to say, the entire architecture of language is arranged along functional lines. Language is as it is because of the functions in which it has evolved in the human species".

${ }^{2}$ No original: "A language is a resource for making meaning, and meaning resides in systemic patterns of choice".
} 
oposto de palavras isoladas ou sentenças colocadas no quadro negro.

Um texto pode ser oral e/ou escrito. Quando escrevemos/falamos, o texto parece ser um conjunto de sentenças; todavia, ele é realmente construído pelo sentido que deve ser expresso por meio de palavras ou estruturas, a fim de produzir a comunicação. Nessa perspectiva, o texto passa a ser resultado de escolhas, sendo que, para Fuzer e Cabral (2014), o lugar social dos autores interfere nas escolhas linguísticas.

Na visão de Halliday (1998), texto se constitui opção e uma corrente contínua de seleções. Segundo Halliday e Hasan (1989), o texto pode ser visto como produto e como processo: "produto" no sentido de ser um "output"/produto, algo que pode ser representado em termos sistemáticos; "processo" como um processo contínuo de escolhas semânticas, um movimento por meio da rede de significados potenciais, com cada conjunto de escolhas que constituem o ambiente para posteriores conjuntos.

Kress (2003, p. 83, tradução minha) define texto como sendo o resultado de ação social. Para ele, o texto "[...] é o resultado de ação semiótica social da representação"3. Destarte, texto é produção. Kress (2003) ressalta dois pontos importantes. Primeiramente, refere-se às questões relacionadas aos participantes dentro de eventos sociais, a saber: quem são os participantes envolvidos, o papel social desempenhado por eles, a proposta de comunicação, as relações de poder, e o ambiente de produção. $\mathrm{O}$ autor reforça a ideia de serem essas questões que formatam os gêneros a serem produzidos em cada situação comunicativa. Em segundo lugar, faz referência às questões sociais, como qual o problema de comunicação e o que será dito.

A partir do supra apresentado, esclareço que este trabalho apoia-se em uma visão de texto diferente de conjunto de frases ordenadas, mas sim, como sendo resultado de ação semiótica e construído a partir de múltiplas fontes de linguagem, não somente o código verbal. Na sequência, apresento discussões referentes à Semiótica Social, que são necessárias para fundamentar as análises.

\section{Semiótica social: termos essenciais; uma base importante}

Para Kress e van Leeuwen (2006), a Semiótica se desenvolveu nos últimos 75 anos e três escolas marcaram o seu aparecimento. A primeira foi a escola de Praga, entre 1930 e o início de 1940, que foi desenvolvida a partir da base linguística de formalistas russos. A

\footnotetext{
${ }^{3}$ No original: "Text is the result of the social semiotic action of representation".
} 
segunda foi a escola Francesa, no período de 1960 e 1970, voltada para as ideias de Saussure, relacionadas ao signo linguístico, ou seja, ao significante e significado, concepções essas que são ensinadas frequentemente em inúmeros cursos de mídia, artes, design, entre outros. A terceira escola refere-se à Semiótica Social (SS) e deriva dos estudos de Michael Halliday. Segundo Natividade e Pimenta (2009), o foco da SS incide sobre o processo de significação, situando-o como parte da construção social. Vale dizer que este trabalho apoiar-se-á nas discussões relacionadas à terceira escola: a Semiótica Social.

O termo Semiótica é definido por Hodge e Kress (1988) como sendo o estudo da semiose, isto é, dos processos e efeitos da produção, reprodução e circulação de significados em todas as formas, por todos os tipos de agentes da comunicação. Nesse sentido, para Halliday e Hasan (1989), o conceito de Semiótica deriva-se inicialmente do conceito de signo linguístico e pode ser definida como o estudo dos signos, assim como discutido por Saussure nos seus estudos.

No entendimento de Saussure, o signo é composto por um significante e um significado. É importante ressaltar que os estudos de Saussure inserem-se em uma corrente formalista, por isso o autor não considera os aspectos externos à língua, como, por exemplo, os contextos de produção, cultura e situação. O que difere os estudos de Halliday dos de Saussure é o fato daquele interpretar o signo linguístico a partir de fatores extrínsecos à língua, por essa razão prefere usar o termo Semiótica Social.

Já Saussure vê o signo de maneira arbitrária: “[...] (pelo menos na linguagem verbal) não há nenhuma conexão necessária ou 'natural' entre um significado e seu significante"4 (HODGE; KRESS, 1988, p. 21, tradução minha). Na visão da LSF (HALLIDAY; HASAN, 1989), há outras formas de significação para além do signo linguístico dentro dele mesmo, pois a língua é somente um dos meios para expressar significados dentro de um sistema mais amplo que envolve, por exemplo, artes, pintura, gestos, música, dança, entre outros. Sendo assim, a construção dos significados ocorre pela integração de vários recursos semióticos (sons, imagens, gestos, cores...).

Kress (2003) rejeita a ideia de arbitrariedade dos signos. Ele parte da Teoria Sistêmico-Funcional da linguagem e entende que a relação entre significante e significado é sempre motivada e não convencional, - o significante, seu "formato", materialmente ou abstratamente considerada, é escolhido por causa de sua aptidão para expressar o que está para ser significado.

\footnotetext{
${ }^{4}$ No original: "[...] (in verbal languages at least) there is no necessary or 'natural' connection between a signified and its signifier".
} 
Nessa direção, segundo Natividade e Pimenta (2009, p. 21), “[...] o ponto central da semiótica é a noção de signo e, para a Semiótica Social, a ênfase recai sobre o processo de produção do signo". Conforme as autoras, isso implica a compreensão de que o signo não é uma conjunção preexistente de significante e significado, mas um processo de produção sígnica no qual os estratos de significante e significado podem ser tratados de forma relativamente independente um do outro. Assim, para elas, o foco da Semiótica Social passou do signo para a maneira como as pessoas usam os recursos semióticos para produzirem significados.

O termo "Interesse" é decisivo dentro dessa teoria, pois, conforme Kress (2010), é a partir do "Interesse" que o produtor escolhe os recursos mais adequados para comunicar os significados. Em outras palavras, dentre os inúmeros recursos semióticos disponíveis, o produtor irá fazer opções de uso de um modo em detrimento do outro, de acordo com seus objetivos de produção. No entanto, Kress (2010) lembra que cada modo semiótico oferece potencial e impõe limitações. A depender do interesse do produtor, o modo verbal torna-se mais eficaz; em outros casos, o não verbal comunica de maneira mais eficiente os sentidos. Atualmente, por exemplo, com os recursos tecnológicos disponibilizados pelas tecnologias digitais, enviar um áudio ou um vídeo pode oferecer uma comunicação mais pertinente e dinâmica.

Ainda na visão de Natividade e Pimenta (2009), essas questões garantem uma diferença reveladora entre a Semiótica Tradicional, chamada por elas de "Semiótica Convencional", e a Semiótica Social. Hodge e Kress (1988) tecem críticas no que se refere à Semiótica Tradicional. Segundo os autores, ela enfatiza as estruturas e os códigos em detrimento das funções e dos usos sociais dos sistemas semióticos. Os autores assumem que a Semiótica Tradicional entende que os significados são congelados e fixos no próprio texto e que devem ser extraídos e decodificados pelos leitores, a partir de um sistema de codificação que seria impessoal, neutro e universal para todos os usuários do código.

Diferentemente, a Semiótica Social não aceita a concepção de que os textos produzem exatamente os significados que os autores esperam serem produzidos, mas são resultados incertos que devem ser estudados no âmbito da ação social, uma vez que seus efeitos são importantes para a construção e a produção de sentido. Nesse processo de significação, o usuário da língua possui um papel agentivo em termos de produção oral e escrita e de recepção de leitura e compreensão oral. É através dele, de suas experiências e conhecimento de mundo que os sentidos são construídos; dessa maneira, um mesmo texto produzido por um autor, com intenções específicas, pode gerar diferentes interpretações a depender de cada 
interlocutor.

Como já dito, o interesse na Semiótica Social está na produção do signo, que é entendido como sendo a fusão entre forma e significado em sua totalidade. Para Kress (2003, p. 37 tradução minha), signo é sempre percebido de maneira integrada "[...] forma-comosignificado e significado-como-forma" ${ }^{5}$. O signo é o coração da unidade semiótica, a fusão entre forma e significado. O signo existe em todos os modos; os diversos modos semióticos precisam ser considerados na produção de sentido, não somente o código verbal.

Segundo Kress (2010), em SS, os indivíduos, com suas histórias sociais, individualmente formatadas, localizadas em ambientes sociais, usam fontes culturalmente disponíveis na produção dos signos e na comunicação, exercendo um papel agentivo. O autor considera que os signos são sempre produzidos de acordo com o interesse do produtor em um ambiente social específico, de acordo com a necessidade do produtor no momento da produção. Nas palavras de Kress (2003, p. 44, tradução minha),

[...] a teoria demanda que nós assumamos o fato de que todos os aspectos do signo representam o interesse dos produtores em representar que eles consideram mais saliente no momento da produção, relacionado ao objeto ou o fenômeno a ser representado. Isso implica que todos os aspectos da forma são significativos, e devem ser lidos de maneira igual. Nenhum elemento dever ser desprezado ${ }^{6}$.

Segundo Kress (2010), todos os signos são feitos de acordo com duas perspectivas e interesses: (1) a do produtor, que os relaciona com suas representações e interesses; (2) e a do recebedor "receiver", que se refere à comunicação e à necessidade de levar em conta seus interesses e as relações de poder. $\mathrm{O}$ autor adverte que esse processo de comunicação deve ser transparente e claro: não deve haver nenhum obstáculo entre o produtor e o recebedor na transmissão da mensagem.

O recebedor, a quem Kress (2010) denomina de "receiver", interpreta a mensagem comunicada pelo produtor em forma de signo. Essa interpretação é interna ao indivíduo. O interlocutor percebe a forma - o significante - por meio dos sentidos e atribui o significado de acordo com suas vivências, conhecimento de mundo e contexto no qual o signo circula. Dessa maneira, a interpretação de um signo não é fixa nem congelada como visto na Semiótica Tradicional. Ao contrário, depende das vivências e dos interesses do interlocutor, podendo um mesmo signo ser representado (internamente) de maneiras diferentes, como vimos no

\footnotetext{
${ }^{5}$ No original: "[...] the sign is always meaning-as-form and form-as-meaning".

${ }^{6}$ No original: “[ $[.$.$] theory demands that we assume that all aspects of a sign represent their maker's interest in$ representing that which they regarded as most salient, at this moment, about the subject or phenomenon to be represented. It entails that all aspects of form are meaningful, and that all aspects of form must be read with equal care: nothing can be disregarded".
} 
exemplo apresentado anteriormente. A seguir, passo a apresentar a metodologia utilizada nesta pesquisa.

\section{Metodologia}

A metodologia aplicada neste trabalho foi a Pesquisa Participante (PP). Para Severino (2007, p. 120), Pesquisa Participante é aquela em que o pesquisador, para observar os fenômenos, compartilha a vivência dos participantes, colocando-se em uma postura de identificação com os pesquisados, interagindo em todas as situações e acompanhando as ações praticadas pelos sujeitos. Nesse tipo de pesquisa, o observador realiza anotações de tudo que foi percebido, além de proceder à análise do que é observado ao longo do período em que convive com os pesquisados.

A PP, dentro de uma perspectiva de ação social, vai além da coleta de dados puramente: ela torna "[...] o trabalho científico de pesquisa de dados uma atividade também pedagógica e, de certo modo, também assumidamente política” (BRANDÃO, 2006, p. 23).

Participaram efetivamente da pesquisa 35 alunos do primeiro ano do Curso de Logística Integrado ao Ensino Médio, sendo 24 do sexo feminino e 11 do sexo masculino, com idade entre 14 a 16 anos. Esclareço que a escolha da turma foi propositalmente pensada, pois havia o interesse em verificar qual o nível de conhecimento de língua inglesa os recémingressados na instituição possuíam e quais as concepções de língua e de linguagem que permeavam suas representações sobre o processo de ensino e aprendizagem de língua inglesa.

Os dados que serão apresentados e analisados neste artigo foram coletados por meio de um questionário e de uma amostra de atividade. Informo que, por questões éticas, usaramse pseudônimos para identificar os participantes da pesquisa, e os excertos apresentados não passaram por correções, a fim de manter a sua originalidade. Segue a proposta de atividade.

\section{Proposta de atividade: leitura de texto imagético}

Essa proposta de atividade consistiu na leitura de um texto imagético, sobre o qual os alunos deveriam responder quatro perguntas de compreensão textual, que foram analisadas com base na Semiótica Social. Ansiei que os alunos percebessem que o texto é "[...] constituído tanto por palavras, frases e períodos, quanto por recursos não verbais como as imagens, as cores e o design gráfico, que compõe seu leiaute" (COSCARELLI; CAFIERO, 2013, p. 16). Segue a imagem utilizada: 


\section{ARE STEREOTYPES KEEPING WOMEN AWAY FROM SCIENCE?}

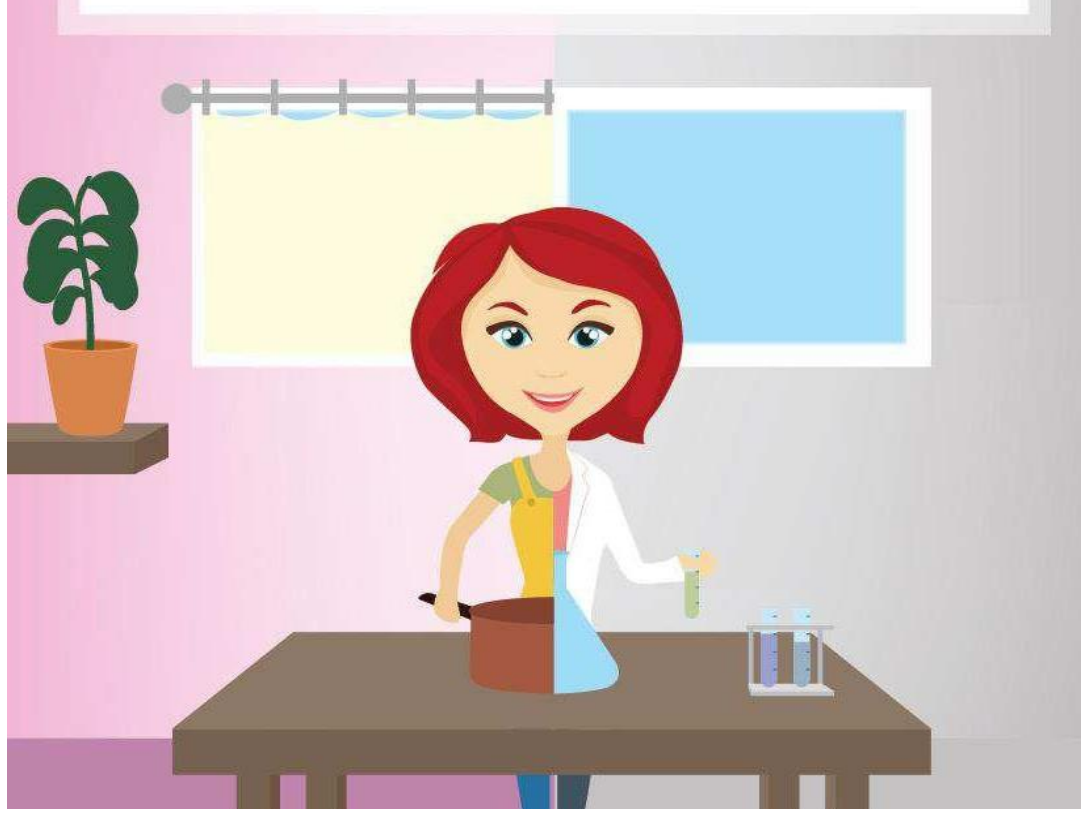

FIGURA 1 - Texto imagético

Fonte: PINTEREST (n. d., n. p.)

Segundo Carvalho e Aragão (2015, p. 15), para ler, atualmente, o indivíduo precisa ser letrado também visualmente. Dito isso, recorro ao Letramento Visual que é entendido como sendo a capacidade desenvolvida pelo indivíduo, a fim de atribuir/produzir significados aos textos, a partir do uso/combinação de diversos modos semióticos, não somente o verbal. Para Serafini (2014), o aumento das imagens visuais não assegura que os alunos estão prestando mais atenção a elas, por isso, faz-se necessário que a escola insira esses conhecimentos nos currículos.

Ao analisar a Figura 1, entendo que se trata de um conjunto multimodal: "[...] combina o código verbal, elementos de design, e imagens visuais"7 (SERAFINI, 2014, p. 2, tradução minha); assim, “[...] em alguns textos a escrita é dominante, enquanto em outros há pouca ou nenhuma escrita"8 (JEWITT, 2005, p. 316, tradução minha). No caso desse texto específico, pode-se perceber que o código não verbal foi dominante. Assim, constato que a escrita é somente um modo semiótico, entre tantos outros, no processo de produção dos sentidos.

\footnotetext{
${ }^{7}$ No original: "[...] combines written language, design elements, and visual images".

${ }^{8}$ No original: "In some texts writing is dominant, while in others there may be little or no writing". 
Retomo aqui o que foi mencionado por Kress (2010): cada modo semiótico oferece potencial e impõe limitações. Se os significados presentes nessa imagem fossem representados pelo código verbal unicamente, possivelmente não causariam o mesmo impacto e, talvez, não despertassem a atenção do leitor para a leitura. Isso reforça, como visto, a importância das escolhas e do Interesse na construção do signo para a produção de sentido e ilustra o que foi apresentado por Natividade e Pimenta (2009). Com base em Kress e van Leeuwen (2006), as autoras pontuam que quem produz um signo realiza escolhas sobre o que considera ser a representação mais adequada do que se deseja transmitir, e esse processo de escolha é guiado pelo interesse que orienta a seleção dos atores sociais conduzidos por meios formais de representação e comunicação. Para complementar, segundo Carmo (2014), no processo de construção dos significados, faz-se necessário realizar escolhas que, de certa forma, direcionam o significado das mensagens como um todo. A seguir, apresento e discuto os dados coletados por meio de questionário e de amostras de atividades.

\section{Análise de dados - Leitura de texto imagético}

Por meio de questionário, perguntei aos participantes: "Se o autor tivesse produzido um texto verbal sem imagens, você acha que produziria o mesmo efeito?". Dos 29 questionários respondidos, 22 disseram que não e apresentaram justificativas, tais como:

\footnotetext{
Não, pois não teríamos refletido tanto o texto (ANTÔNIO).

Não, pois a imagem faz com que, ao lermos o texto, reflitamos sobre o texto, fato que é dificultado sem a imagem (JACINTO).

Não, pois a imagem complementou o texto escrito e produziu um design atrativo para o público (LUÍZA).

Não, porque a imagem enfatiza a parte escrita, causando um efeito melhor (LETÍCIA).
}

Pelas respostas, percebo que o código verbal complementa o não verbal e que ambos devem ser associados na produção dos sentidos. Assim, segundo Kalantzis e Cope (2012, p. 2, tradução minha), “[...] significado é produzido de maneira a ser cada vez mais multimodal nos quais os modos linguísticos escritos de significação estabelecem interface com o oral, visual, auditivo, gestual, tátil e espacial"9". Ainda nesse sentido, conforme Kress (2003), nenhum elemento deve ser desprezado.

\footnotetext{
${ }^{9}$ No original: "Meaning is made in ways that are increasingly multimodal - in which written-linguistic modes of meaning interface with oral, visual, audio, gestural, tactile and spatial patterns of meaning".
} 
No que se refere à leitura, o depoimento de Antônio confirma que houve uma reflexão sobre o texto, não somente uma decodificação; apoio essa afirmação no uso da palavra "refletir". Assim, recorro às palavras de Coscarelli e Cafiero (2013, p. 16), quando afirmam que ler não é tarefa fácil e se configura como uma atividade complexa, a qual exige que o leitor participe ativamente do processo de leitura: “[...] ele não 'recebe' sentidos prontos, mas age sobre o texto e os processa, (re)construindo sentidos a partir de suas próprias experiências de mundo, de seus conhecimentos, de suas crenças".

Os depoimentos fazem ainda uma menção ao público. A participante Luíza percebeu que o designer pensou no interlocutor e orientou suas escolhas a partir disso, produzindo um design mais atrativo. Nesse sentido, como dito por Kress (2010), todos os signos são elaborados de acordo com duas perspectivas: a do produtor e a do interlocutor, e é resultado de um "trabalho semiótico" (KRESS, 2003, p. 37).

$\mathrm{Na}$ sequência, os cinco participantes que responderam "sim" apresentaram os seguintes argumentos:

Sim, pois teria o mesmo questionamento (CRISTAL).

Sim, pois os dois mostraram o que acontece com as mulheres, o que a sociedade faz (ISABELA).

Sim, e poderia ter sido até mais fácil de interpretar, pois o texto verbal costuma ser mais claro (BABI).

Na minha opinião, sim, porque facilitaria o leitor entender o autor, a sua reflexão (SELENA).

Sim, porém talvez deixasse o texto menos interessante (IAGO).

Quando os alunos dizem que seria mais fácil, entendo que eles remetem ao texto verbal como pronto, acabado, cujos significados já foram definidos pelo autor previamente, como é dito por Selena: “[...] facilitaria o leitor entender o autor, sua reflexão”. Nesse sentido, a reflexão é posta pelo autor e não construída pelo leitor, de maneira que haveria uma interpretação única, aquela determinada pelo autor, o que na visão do participante seria mais fácil. Isso vai de encontro às reflexões embasadas na Semiótica Social, uma vez que esta não concebe que os textos produzem exatamente os significados que os autores esperam serem produzidos, eles são resultados incertos que devem ser estudados no nível da ação social.

Por fim, uma outra participante disse: "talvez, estaria (sic) faltando alguns elementos, mas seria possível entender" (SOFIA). Na visão da participante, a mensagem até poderia ser entendida, mas ela concorda que estariam faltando alguns elementos.

Diante disso, são exigidas dos leitores outras capacidades, não somente a de 
decodificar e de localizar informações no texto. Evidencia-se que a lógica para leitura de textos multimodais/visuais é diferente da leitura de textos predominantemente verbais. É fundamental a observação de todos os elementos que compõem o signo imagético, de maneira que não existe um caminho de leitura fixo, que inicie da direita para a esquerda e de cima para baixo por meio do código verbal; os leitores poderão seguir caminhos diferentes de leitura, iniciar por pontos distintos, como expressado por Serafini (2011, p. 343, tradução minha): "[...] Esses textos desafiadores requerem que os leitores trabalhem através de múltiplos sistemas de signos, e usem diferentes estratégias para navegá-los e compreendê-los" ${ }^{\prime 10}$.

Ainda sobre leitura de texto imagético, interroguei: "Por onde você iniciou a leitura da imagem? Se você iniciasse por outro ponto, seria possível entender a mensagem? Por quê?” Os dados estão disponíveis no Quadro 1.

Os dados comprovam que, para a leitura de signos imagéticos, não há uma ordem predefinida; os participantes revelam claramente terem começado por elementos diferentes, não seguindo uma ordem fixa. Nesse sentido, o caminho de leitura pode ocorrer em círculos, sendo menos codificado. Kress e van Leeuwen (2006, p. 205, tradução minha) ${ }^{11}$ dizem que “[...] diferentes leitores poderão seguir diferentes caminhos". Foi o que ocorreu nesta pesquisa.

Os participantes relacionaram a palavra "stereotype", presente na parte verbal, com os elementos dispostos pelo não verbal: pode-se dizer que "[...] imagem e palavras mantêm uma relação cada vez mais próxima, cada vez mais integrada” (DIONÍSIO, 2011, p. 138). Houve também uma relação entre o texto e o papel social esperado pela sociedade, que a mulher desempenhe tarefas domésticas. Os depoimentos, de maneira implícita, fazem alusão à frase que circula socialmente: "lugar de mulher é na cozinha". Assim sendo, ler “[...] não se esgota na decodificação pura da palavra escrita ou da linguagem escrita [...]. A leitura de mundo precede a leitura da palavra" (FREIRE, 2011, p. 19).

\footnotetext{
${ }^{10}$ No original: "These challenging texts require that readers work across multiple sign systems and use different strategies for navigating and comprehending these texts.

${ }^{11}$ No original "Different readers may follow different paths". 


\begin{tabular}{|l|c|l|}
\hline \multicolumn{1}{|c|}{$\begin{array}{c}\text { PONTO DE } \\
\text { PARTIDA DA } \\
\text { LEITURA }\end{array}$} & $\begin{array}{c}\text { NÚMERO } \\
\text { DE } \\
\text { ALUNOS }\end{array}$ & \multicolumn{1}{c|}{ EXCERTOS } \\
\hline $\begin{array}{l}\text { Início da leitura pelo } \\
\text { código verbal }\end{array}$ & 11 & $\begin{array}{l}\text { "Pelo texto escrito" (ISABELA). } \\
\text { "Título" (MARIA CLARA). } \\
\text { "Iniciei pela parte escrita" (CRISTAL). }\end{array}$ \\
\hline $\begin{array}{l}\text { Início pelo centro } \\
\text { e pela imagem da } \\
\text { mulher }\end{array}$ & 3 & $\begin{array}{l}\text { "Pelo desenho da mulher" (ASHLEY). } \\
\text { "Pela mulher" (AMERICANO). } \\
\text { "Iniciei a leitura pelo centro, ou seja, pela mulher" } \\
\text { (CATARINA). }\end{array}$ \\
\hline Início pela divisão & 3 & $\begin{array}{l}\text { "Pela divisão" (JACINTO). } \\
\text { "Iniciei a leitura da imagem pela divisão existente entre os } \\
\text { lados presentes na ilustração" (LACIE). } \\
\text { "Pela divisão dos cenários"(KATHERINE). }\end{array}$ \\
\hline $\begin{array}{l}\text { Início pelas cores } \\
\text { e pelos elementos } \\
\text { não verbais }\end{array}$ & 9 & $\begin{array}{l}\text { "Eu iniciei a leitura pelas cores" (SELENA). } \\
\text { "Pelos objetos e cores" (PEDRO). } \\
\text { "Pela parte visual dos desenhos" (LETÍCIA). }\end{array}$ \\
\hline Início pela mesa & 1 & "Iniciei a leitura do texto pela mesa" (JEAN GREY). \\
\hline Início pela cozinha & 1 & "Iniciei pelo lado que representava a cozinha" (LUIZA). \\
\hline $\begin{array}{l}\text { Deixou a questão em } \\
\text { branco }\end{array}$ & 1 & \multicolumn{2}{|l}{ Q } & & \\
\hline
\end{tabular}

QUADRO 1 - Resultados da pesquisa sobre caminhos de leitura

Fonte: dados da pesquisa.

A seguir, apresento análises com a intenção de relacionar as respostas dos alunos com os objetivos traçados ao preparar essa atividade de interpretação textual. Esperei, inicialmente, que os alunos lessem a imagem relacionando o verbal com o não verbal. Com base nas respostas, pode-se perceber que houve uma relação entre o verbal e o não verbal. Seguem dois exemplos:

This text is about the stereotypes that make the women away from science, as the stereotype that the women have to take care of the house and the family to the detriment of their job and career (LACIE).

The text is about the womans and the stereotypes of she have to stay only in the kitchen (ISABELA).

Posteriormente, esperei que os alunos observassem as cores presentes na imagem e estabelecessem relação com os significados que respresentam socialmente, referente ao gênero masculino e feminino. Nesse sentido, temos como respostas:

A imagem da moça dividida de maneira machista com cores dadas como de mulher e homem separadamente (LU).

Os gêneros de forma geral é um assunto bastante discutível. Podemos ver isso através da imagem trabalhada, a mulher pode ter estereótipos de que a cor usar, que serviço prestar (CATARINA).

A participante Lu entendeu a imagem de forma machista, uma vez que ela foi separada em cores, o rosa representando o lado feminino, acrescento, com elementos que remetem à 
cozinha de uma casa com precisão de detalhes. No lugar do tubo de ensaio, a mulher segura uma panela. Já o lado azul (dos homens) é representado pela ciência. O que nos permite pensar que ciência é para homem e cozinha é para mulher. Parte da mulher está, ou poderá estar, na ciência, mas nenhum elemento masculino se encontra presente no que se considera lado feminino. Em outras palavras, os alunos mencionam o fato de a mulher estar inserida na ciência, mas esqueceram de pontuar que o contrário não acontece na imagem.

Por último, desejei que os alunos comparassem o posicionamento do vaso de planta, da panela, do tubo de ensaio com as representações de homem e de mulher na sociedade. Seguem os exemplos para ilustrar.

\footnotetext{
Alguns elementos presentes no texto são uma panela e um tubo de ensaio, a panela significando o estereótipo que a mulher tem que cozinhar e o tubo de ensaio significando que ela pode fazer outra coisa além de atividades domésticas (IAGO)

O Jaleco e os tubos de ensaio mostrando o lado da ciência e a panela e a planta mostrando estereótipo da mulher dona de casa (JEAN GREY).
}

Observei que os participantes compararam os elementos presentes na imagem com as representações sociais da mulher, estabelecendo relação entre os elementos do lado rosa e as representações de mulher na sociedade, como ser dona-de-casa. Mas, para o participante Iago, a imagem passa a ideia de que a mulher "pode fazer outra coisa além de atividades domésticas". Sabemos que existem mulheres na ciência, na fábrica, no transporte, na mecânica, na engenharia, todavia vale lembrar que em menores proporções se comparada com os homens.

Reforço o fato de os alunos, em sua maioria, não terem percebido e não textualizarem o fato de o lado azul representar um espaço predominantemente masculino. Ocorre-me que talvez isso não esteja claro na imagem e faça sentido somente para mim, devido as minhas experiências individuais sobre o tema e meu conhecimento de mundo. O que nos remete à visão de texto desenvolvida dentro da perspectiva da semiótica social: os significados não são fixos nem únicos.

Por meio dos dados coletados, certifiquei que não existiu uma representação única, leitores diferentes atribuíram significados diferentes. Por um lado, houve quem entendesse a imagem como sendo machista e reforçando o estereótipo de que a mulher deve ser dona de casa, como disse a participante Maria Clara: “[...] a imagem e o texto trazem uma representação machista sobre a mulher e sua capacidade de fazer as coisas. Tentando impor que o lugar de mulher é na cozinha, arrumando casa e criando os filhos, não podendo transmitir o seu conhecimento e sua capacidade ao mundo". Por outro lado, a participante 
Babi afirmou:

The text shows two views of a woman, that she may be a house woman or a scientist, or both at the same time because of the evolution. The woman wears pink represent a stereotype, but other lado show a woman with elements showing profession scientist.

Na visão de Maria Clara, a imagem reforça o estereótipo feminino da mulher como dona de casa. Babi, porém, acredita que a imagem retrata o fato de a mulher desempenhar outras funções, não somente a de ser dona de casa. Para ela, segundo a imagem, a mulher pode ser dona de casa, cientista e/ou as duas coisas simultaneamente. Essa questão conduz meu pensar ao fato de que os significados são construídos socialmente e são individuais.

Dentro dessa proposta de leitura, não existe uma interpretação única e correta, já que nem sempre a resposta do professor ou o livro do professor são as ideais. Há que se pensar a partir do ponto de vista do aluno: do outro. Nessa linha de raciocínio, os significados são construídos a partir das individualidades do leitor, ou seja, ler consiste em estabelecer ligações entre o texto e o conhecimento do leitor, suas experiências e seus interesses (KALANTZIS; COPE, 2012). É importante ressaltar que apesar de haver um significado social no uso do azul e do rosa na imagem, sabemos que cor não determina gênero.

\section{Considerações finais}

Com este trabalho, propus defender a tese de que outros modos de significação, não somente o código verbal, precisam ser levados para a sala de aula durante as práticas de leitura de textos, que, de acordo com Kress (2000), são multimodais. Com base em Kress (2003), busquei conscientizar o aluno de que os textos contemporâneos produzidos em tela se tornam cada vez mais visuais e que, para construir significados a partir desses textos, tanto na recepção, como na produção, é fundamental observar os diversos modos semióticos presentes; sendo que, como dito por Kress (2010), cada modo semiótico apresenta potenciais e limitações.

Durante o processo de leitura, os alunos foram além da decodificação do código verbal e simples localização de informação. Eles fizeram inferências, comparações, relacionaram a mensagem com os seus conhecimentos de mundo e se posicionaram de maneira crítica diante dos textos lidos, tendo a oportunidade de concordar ou refutar a opinião do autor.

Com as atividades de interpretação, observei a não existência de um significado único; diferentes leitores atribuíram diferentes significados ao mesmo texto, mas sempre de forma 
coerente e possível, levando em conta experiências individuais, conhecimento de mundo, contexto social e econômico em que estão inseridos. Com isso, constato o defendido pela Semiótica Social: os significados não são fixos e congelados no próprio texto, e sim construídos pela interação entre o leitor e o texto, de maneira tal que diferentes leitores podem atribuir significados diferentes ao mesmo texto. Sendo assim, esperei que os alunos-leitores construíssem significados a partir do texto lido e não somente extraíssem os significados prontos a partir de uma visão única e fechada.

Com base nisso, reforço o fato de os textos imagéticos exigirem que o leitor relacione a leitura com as representações sociais acerca do tema, combinando os diversos modos semióticos presentes na imagem. Em outras palavras, faz-se necessário focar no estudo do signo em sua totalidade, vinculando-o aos aspectos sociais, culturais, políticos e econômicos, para a produção de sentido; assim, não há um significado universal para os signos, como vimos por meio das respostas dos participantes.

\section{REFERÊNCIAS}

BRANDÃO, C. R. A pesquisa participante e a participação da pesquisa: um olhar entre tempos e espaços a partir da América Latina. In: BRANDÃO, C. R.; STRECK, D. R. (org.). Pesquisa participante: a partilha do saber. 4. ed. São Paulo: Ideias \& Letras, 2006. p. 17-54.

CARMO. C. M. O lugar da cultura nas teorias de base linguística sistêmico-funcional. Curitiba: Editora Appris, 2014.

COSCARELLI, C. V.; CAFIERO, D. Ler e ensinar a ler. In: COSCARELLI, C. V. (org.). Leituras sobre a leitura. Belo Horizonte: Vereda, 2013. p. 9-35.

CARVALHO, S. A.; ARAGÃO, C. de O. Os caminhos do letramento visual: uma análise de material didático virtual. Revista Estudos Anglo-Americanos, Florianópolis, n. 44, p. 9-34, 2015.

DIONÍSIO, A. P. Gêneros textuais e multimodalidade. In: KARWOSKI. A. M.;

GAYDECZKA. B.; BRITO. K. S. (org.). Gêneros textuais: reflexões e ensino. 4. ed. São Paulo: Parábola Editorial, 2011. p. 137-52.

FUZER, C.; CABRAL, S. R. S. Introdução à Gramática Sistêmico-Funcional em Língua Portuguesa. São Paulo: Mercado de Letras, 2014.

FREIRE, P. A importância do ato de ler: em três artigos que se completam. 51. ed. São Paulo: Cortez, 2011.

HALLIDAY, M. A. K. El languaje como semiótica social - la interpretación social del 
lenguaje y del significado. Santafé de Bogotá, Colômbia: Fondo de Cultura Econômica, 1979.

HALLIDAY, M. A. K.; HASAN, R. Language, context, and text: aspects of language in a social-semiotic perspective. Oxford: Oxford University Press, 1989.

HALLIDAY, M. A. K.; MATTHIESSEN, C. M. I. M. An introduction to Functional Grammar. London : Hodder Education, 2004.

HODGE, R.; KRESS, G. Social Semiotics. Cambridge: Polity Press, 1988.

JEWITT, C. Multimodality, "reading" and "writing" for the 21st century. Discourse: Studies in the Cultural Politics of Education, London, v. 26, n. 3, p. 315-332, 2005.

KALANTZIS, M.; COPE, B. Literacies. Cambridge (UK): Cambridge University Press, 2012.

KRESS, G. Multimodality. In: COPE, B.; KALANTZIS, M. (ed.). Mutlitliteracies: literary learning and the design of social futures. London: Routledge, 2000. p. 182-202.

KRESS, G. Literacy in the new media age. London; New York: Routledge, 2003.

KRESS, G. Multimodality: a social semiotic approach to contemporary communication. London: Routledge, 2010.

KRESS, G.; van LEEUWEN, T. Reading images: the Grammar of Visual Design. 2 ed. London; New York: Routledge, 2006.

MARTELOTTA, M. E.; KENNEDY, E. A visão funcionalista da linguagem no século XX. In: CUNHA, M. A. F.; OLIVEIRA, M. R.; MARTELOTTA, M. E. Linguística funcional: teoria e prática. São Paulo: Parábola, 2015. p. 11-20.

NATIVIDADE, C.; PIMENTA, S. A semiótica social e a multimodalidade. In: PIMENTA, S.; AZEVEDO, A.; LIMA, C. (org.). Incursões semióticas: teoria e prática de GSF, multimodalidade, semiótica social e ACD. Rio de Janeiro: Livre Expressão, 2009. p. 21-29.

NEVES, M. de M. Uma visão geral da gramática funcional. Alfa, São Paulo, v. 38, p. 109127, 1994. Disponível em: http://seer.fclar.unesp.br/alfa/article/view/3959. Acesso em: 06 ago. 2016.

RESENDE, V. de M.; RAMALHO, V. Análise de Discurso Crítica. São Paulo: Editora Contexto, 2006.

SANTOS, Z. B. A linguística sistêmico-funcional: algumas considerações. Soletras, Rio de Janeiro, n. 28, p. 164-181, jul./dez. 2014. Disponível em: https://www.epublicacoes.uerj.br/\%20index.php/soletras/article/view/12994. Acesso em: 01 maio 2018.

SERAFINI, F. Expanding perspectives for comprehending visual images in multimodal texts. Journal of Adolescent \& Adult Literacy, Newark, v. 54, n. 5, p. 342-350. 2011.

SERAFINI, F. Reading the visual: an introduction to teaching Multimodal Literacy. New 
York: Teachers College Press, 2014.

SEVERINO. A. J. Metodologia do trabalho científico. 23. ed. São Paulo: Cortez, 2007.

SOUZA. S. A. "Eu aprendi usar outras ferramentas também”: A construção de significados por meio de práticas de leitura e produção de textos multimodais em inglês no ensino médio. 288 f. 2019. Tese (Doutorado em Estudos da Linguagem) - Centro Federal de Educação

Técnica e Tecnológica de Minas Gerais, Belo Horizonte, 2019.

Artigo submetido em: 18 fev. 2021

Aceito para publicação em: 25 maio 2021

DOI: https://dx.doi.org/10.22456/2238-8915.111610 